\title{
Study of the effect of inter-pass temperature on weld overlap start-stop defects and mitigation by application of laser defocusing
}

\author{
Wai Jun Lai ${ }^{1}$ (D) Supriyo Ganguly ${ }^{1} \cdot$ Wojciech Suder ${ }^{1}$
}

Received: 2 September 2020 / Accepted: 25 February 2021 / Published online: 8 March 2021

(C) The Author(s) 2021

\begin{abstract}
Laser keyhole initiation and termination-related defects, such as cracking and keyhole cavities due to keyhole collapse, are a wellknown issue in laser keyhole welding of thick section steels. In longitudinal welding, run-on and run-off plates are used to avoid this problem. However, such an approach is not applicable in circumferential welding where start/stop defects remain within the workpiece. These issues can hinder industry from applying laser keyhole welding for circumferential welding applications. In this paper, the effect of inter-pass temperature on laser keyhole initiation and termination at the weld overlap start-stop region was investigated. This study has identified that defects occurring within this region were due to laser termination rather than laser initiation because of keyhole instabilities regardless of the thermal cycle. The laser termination defects were mitigated by applying a laser defocusing termination regime to reduce the keyhole depth gradually and control the closure of the keyhole.
\end{abstract}

Keywords Laser keyhole welding $\cdot$ Laser keyhole termination $\cdot$ Start/stop defects $\cdot$ Laser defocusing

\section{Introduction}

Laser welding is a flexible welding process capable of joining and manufacturing components in a variety of different materials, from polymers, steels, aluminium alloys, titanium alloys, copper alloys, to nickel-based superalloys, for a wide range of industries, such as medical, electronics, aerospace, automotive, and offshore industries [1-6]. The demand for welding applications capable of joining thick section structural steels in the shipbuilding, oil and gas, and offshore wind industries has led to significant research into laser welding and hybrid laser welding processes [5-8]. The high energy density of laser and hybrid laser welding processes can achieve deep penetration, high aspect-ratio welds at high welding speeds due to material vaporisation, and the formation of a laser keyhole, increasing weld productivity.

A laser keyhole is formed by the vaporisation of the constituent elements within an alloy, which generates a recoil pressure on the liquid metal. The continued evaporation due to the vapour recoil pressure and pressure balances of the

Wai Jun Lai

wai-jun.lai@cranfield.ac.uk

1 Welding Engineering and Laser Processing Centre, Cranfield University, College Road, Cranfield MK43 0AL, UK liquid metal sustains the formed keyhole [9]. The balance of these forces is sensitive to variation in process parameters, making them susceptible to keyhole instabilities and therefore, keyhole collapse. Keyhole instabilities and keyhole collapse can lead to porosity, voids, unfilled keyhole cavities, and weld surface craters and depression [10-13]. These defects also occur when the laser is terminated abruptly and without significant control of the process parameters and melt pool dynamics. As the laser terminates, several phenomena need to be considered, each occurring within a specific time frame. The extinction of plasma within the keyhole, the decay of vaporisation recoil pressure, and the mechanical collapse of the keyhole driven by surface tension forces all occur instantaneously [14]. The imbalance of these driving forces during abrupt laser termination and collapse of the keyhole can lead to bubble formation, as shown by Courtois et al. using numerical simulations validated by experimental observations [15]. The author showed how the liquid metal solidified before the keyhole cavity is filled and gases can escape, resulting in porosity.

Therefore, laser keyhole welding is more applicable for longitudinal welds where run-on and run-off plates can be used to contain any defects generated at the start and stop of the weld seam, and then subsequently removed. In circumferential welding applications of tubular sections, such as pipes, the use of run-on and run-off plates is not feasible. The 
initiation and termination points of the intersecting weld where defects, such as an unfilled keyhole cavity or porosity, are likely to occur remain in the workpiece. When operating in autogenous laser keyhole welding mode where there is no addition of filler material, the filling of a keyhole cavity is much more difficult, especially when the laser is terminated abruptly. Therefore, it is necessary to control the closure of the keyhole at the laser termination point by applying a suitable laser termination regime or procedure. The melt pool dynamics needs to be well balanced during laser termination to achieve a good termination and weld profile, without defects.

Considerable interest has therefore been placed into the prevention of laser weld termination defects. A patent by Becker et al. [16] details various process methods for reducing end crater formations as the laser approaches the end of the weld seam, such as laser defocusing, reduced welding speed, lateral movement of the beam and reducing the laser power, or any combination thereof. Some of these methods may require complex process optimisation and additional equipment, which can be costly and difficult to implement in real conditions. The preferred or most utilised methods of reducing and eliminating these issues are the ramping down of laser power or accelerating the welding speed, or both, due to ease of process control and implementation [13]. However, the gradual reduction in penetration when ramping down the laser power can lead to porosity due to keyhole fluctuation and collapse when welding over a previous weld, as described by Dawes [13]. The speed of the gradual reduction in keyhole depth needs to be optimised to match the solidification rate of the material to avoid defects, such as cracking and cavities. At the same time, the application of accelerating welding speed may lead to melt pool instabilities and increase the solidification rate due to the reduction in heat input.

In recent studies on the mitigation of laser termination defects in autogenous laser keyhole welding of 8-mm-thick sections, Gook et al. have investigated both laser power rampdown and laser defocusing termination methods [17]. The authors show that the transition from full penetration to partial penetration welding is prone to root sagging or solidification crack defects when either laser power ramp-down or laser defocusing is applied. Defects, such as solidification cracks, shrinkage cavities, and weld craters, could not be avoided unless a "smoothing layer", using laser defocusing with a low beam power was applied at the weld overlap. However, such repair procedure increases processing time and may have adverse effects on the weld, microstructural development, and behaviour of the material if not optimised and appropriately applied. The remelting of a previous weld pass can lead to additional segregation and reheat the coarse-grained heat affected zone, which would increase the probability of shearinduced transformation product (e.g. martensite) forming, with subsequent deterioration of toughness. The main applications of laser defocusing are for post-weld laser treatment purposes, such as laser surface remelting to improve the weld topology, microstructure, and mechanical properties. The "smoothing layer" shown by Gook et al. [17] is an example. Further examples were shown by Powell et al. for improving the weld root uniformity [18] and Xu et al. to try and reduce the weld hardness and improve the weld surface profile [19]. There is still little research and application of laser defocusing to mitigate laser termination-related defects due to the difficulties in process control.

The scope of this paper is to identify the causes of defects at the weld overlap start-stop region in autogenous laser welding of circumferential welds and how to mitigate such defects using a process-based method. In this study, the underpinning causes of defects at the weld overlap start-stop region were investigated by replicating different circumferential weld diameters onto flat plates using two overlapping weld seams. Firstly, the formation of defects at the weld overlap start-stop region and the effect of different inter-pass temperatures achieved by replicating different circumferential weld diameters (pipe diameters) were identified. Secondly, controlled experimentation was performed to demonstrate how defects at the weld overlap start-stop region can be eliminated by applying a laser defocusing termination regime.

\section{Experimental procedure}

\subsection{Replicated circumferential weld on flat plate}

A circumferential weld involves the joining of two tubular sections, such as pipes, along the circumference. The start of the weld is overlapped by the intersecting weld seam before termination and remains within the workpiece. The process is simplified by replicating the circumferential weld onto a flat plate with an elongated weld overlap with two partially overlapping weld seams, as shown in Fig. 1. The elongated weld overlap allows for the start and termination points of the laser to be investigated independently of each other.

Each point denoted as, $A, B, C$, and $D$ represents the two initiation points $(A$ and $B)$ and two termination points ( $C$ and $D)$ of the two weld seams, respectively. Firstly, a weld is carried out between the points $B$ and $D$, where the laser initiates at $B$ and terminates at $D$. Then after a calculated time delay, simulating different circumferential dimensions, the laser is reinitiated at point $A$ and then terminated at point $C$. The overlapped $B C$ length $(\overrightarrow{B C})$ represents the elongated weld overlap start-stop region, therefore, replicating a circumferential weld.

The time delay was varied to simulate the welding process of different outer pipe diameters with varying circumferential lengths without increasing the length of the workpiece. These different outer pipe diameters result in different inter-pass 


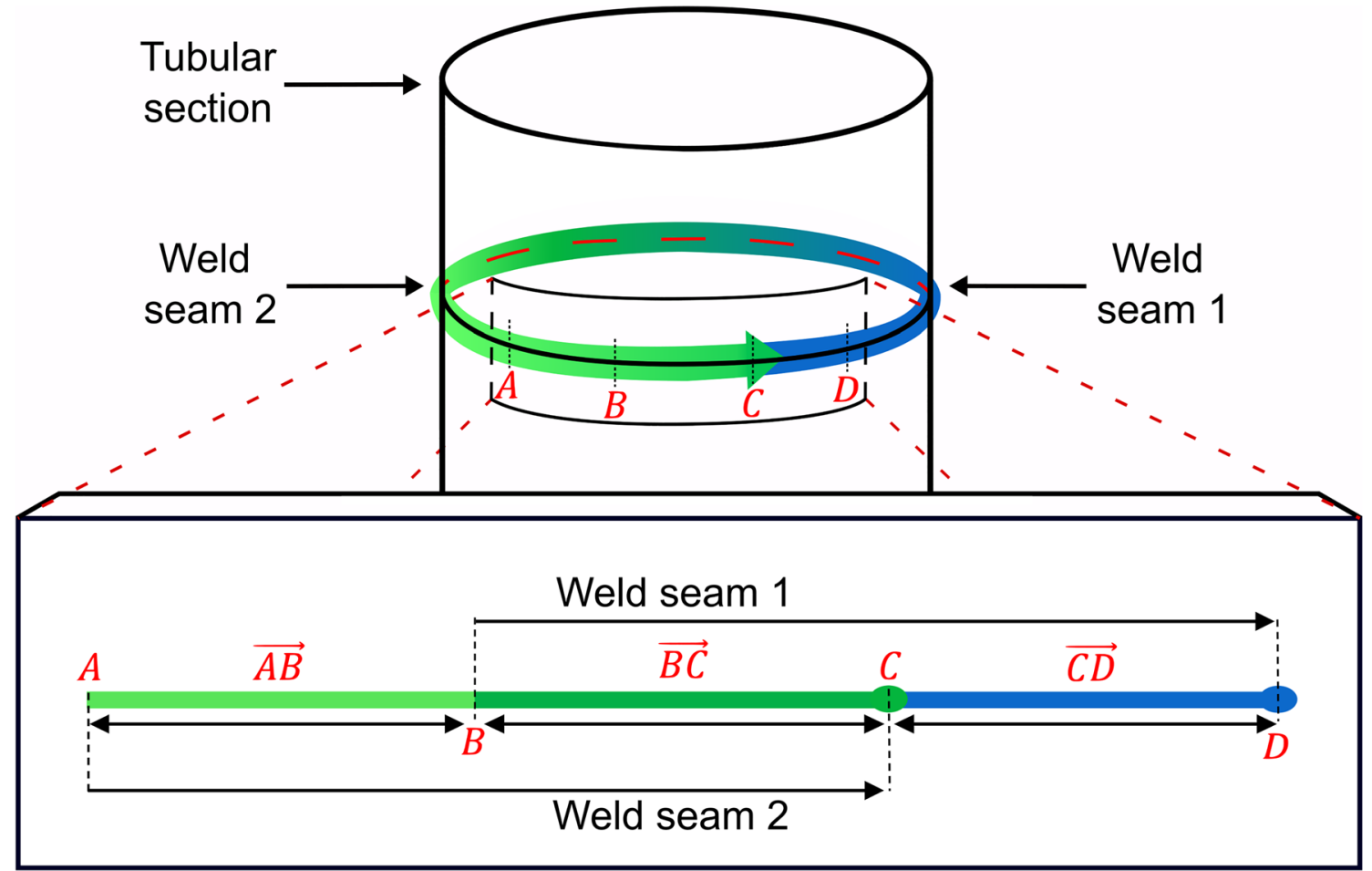

Fig. 1 Illustration of circumferential weld replicated onto a flat plate

conditions as observed in a circumferential weld at the point of overlap due to the residual heat from the first weld (start section of a circumferential weld).

\subsubsection{Time delay between the first and second weld seams}

The delay time, $t_{\text {delay, }}$ between the two weld seams was calculated for different pipe diameters $(D)$ by simulating varying circumferential lengths of travel $\left(L_{\text {circ }}\right)$ at a set welding speed (v). The delay time, $t_{\text {delay }}$, is equal to the time remaining when the following durations have been subtracted from the total calculated time required to weld the circumferential length $(t$ circ). These durations are the time it has taken:

- $\quad$ To weld from point $B$ to point $D\left(t_{\overrightarrow{B D}}\right)$

- For the laser head to travel at the maximum robot motion speed from point $D$ to point $A$, and to start emission $\left(t_{\overrightarrow{D A}}\right)$

- $\quad$ To weld from point $A$ to point $B\left(t_{\overrightarrow{A B}}\right)$.

A simplified expression is given in Eq. (1), where $t_{\overrightarrow{A D}}=t_{\overrightarrow{B D}}+t_{\overrightarrow{A B}}$.

$t_{\text {delay }}=t_{\text {circ }}-t_{\overrightarrow{A D}}-t_{\overrightarrow{D A}}$

\subsection{Experimental setup}

An 8-kW maximum output IPG fibre laser with a fibre diameter of $0.3 \mathrm{~mm}$, a collimation lens with a focal length of
$125 \mathrm{~mm}$ and a focusing lens with a focal length of $250 \mathrm{~mm}$ were used in this study. This setup gave a beam diameter of $0.6 \mathrm{~mm}$ at the focal point. The welds were carried out with the focal point on the plate surface in all experiments. The laser head was tilted by $10^{\circ}$ to avoid back reflection, as shown in Fig. 2. All welds were carried out without shielding gas to minimise any interaction with the vapour plume and melt pool.

S355 low carbon structural steel plates were used, and the chemical composition is shown in Table 1. The plates were cleaned with acetone before welding and after the first weld seam to remove contamination. Two K-type thermocouples were spot-welded onto the top surface of the plates and connected to an oscilloscope to record the time-temperature profile during each weld seam. The plates were clamped in position using a fixture in the $2 \mathrm{G}$ horizontal welding position, as shown in Fig. 2. The location of the thermocouples was equidistant from point $B$ to point $C$, as shown in Fig. 2 .

\subsection{Experimental approach}

Two experiments were conducted to investigate the formation of laser initiation and termination defects at the weld overlap start-stop region when the laser terminates abruptly, and when a laser defocusing termination regime is applied. 

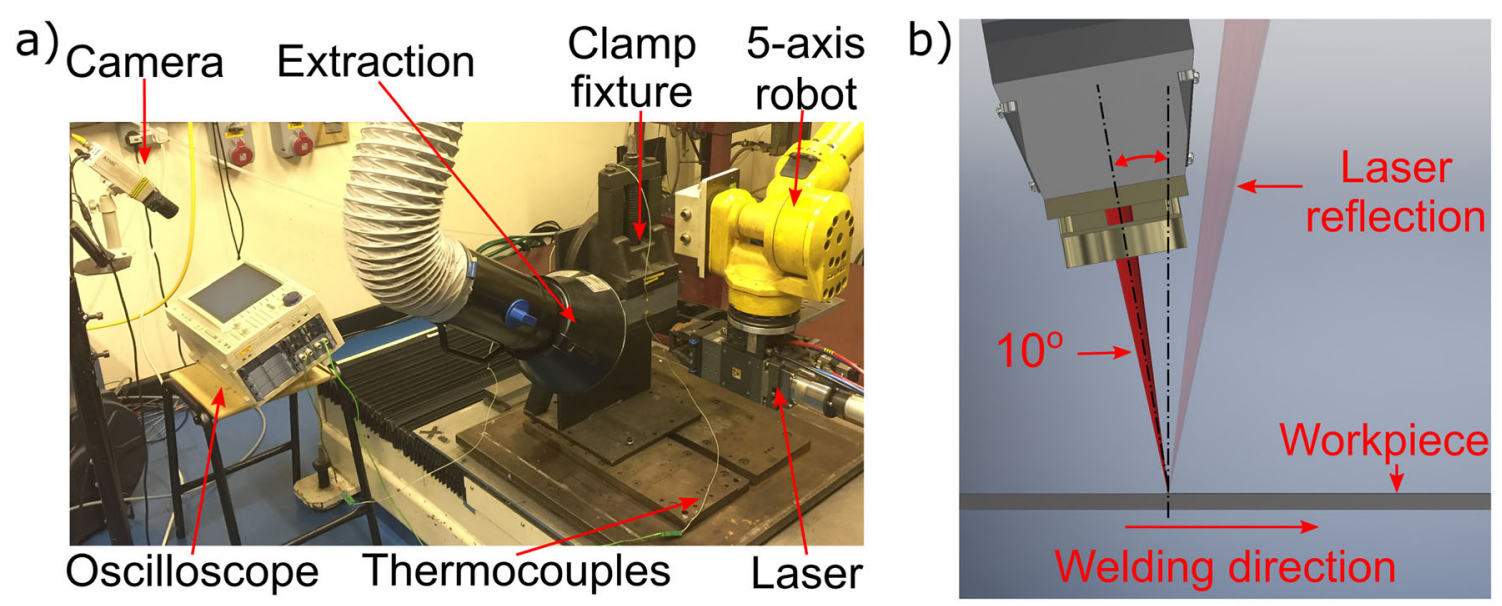

c)

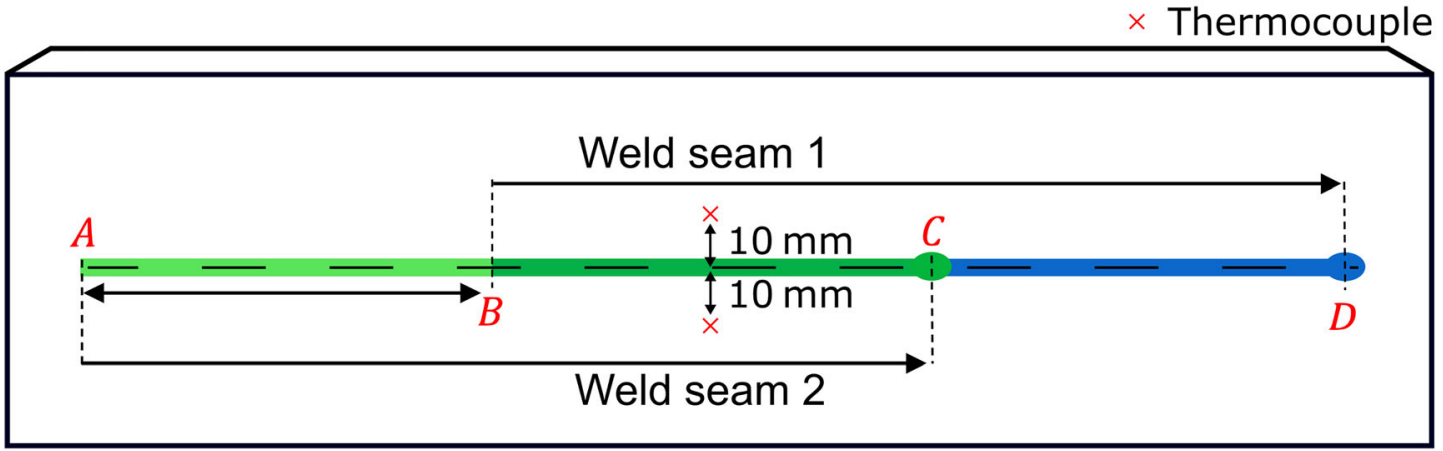

Fig. 2 (a) Experimental set-up. (b) Schematic of laser head angle. (c) Location of thermocouples

\subsubsection{Abrupt laser termination}

No control of the laser initiation or termination was implemented during welding. The laser initiates instantaneously at full power and terminates abruptly from full power to no emission.

\subsubsection{Laser defocusing termination regime}

Laser defocusing is achieved by gradually increasing the distance between the laser head from the workpiece (focal position) while maintaining a constant laser power output. The laser spot diameter was measured at different distances from the optics using a commercial beam profiler. The measured data were then used to generate a linear regression for the laser spot diameter as a function of distance from the laser optics, which was used to achieve the required laser spot diameter. Three laser end spot diameters and three pipe diameters were considered resulting in six weld samples.

\subsection{Process parameters}

The set-up and process parameters used for both experimental approaches are shown in Table 2. The laser power and laser travel speed were calculated using the Power Factor Model, as proposed by Suder and Williams to achieve full penetration [20]. In the laser defocusing termination regime, the plate mill scale was not removed, and some changes to the welding parameters were made to study the worst-case scenario welds. The laser travel speed was reduced, and the laser power adjusted to match the change in speed and the slight difference in plate thickness. The low travel speed generates a large volume of liquid metal that surrounds the laser keyhole, and along with the plate mill scale, would increase the likelihood of defect formation to occur.

\subsection{Sample analysis}

Longitudinal and transverse cross-sections from various areas of the welded samples were cut, mounted, ground, and

Table 1 Chemical composition of S355 low carbon steel, wt $\%$

\begin{tabular}{lllllllllllllllll}
\hline $\mathrm{C}$ & $\mathrm{Mn}$ & $\mathrm{Si}$ & $\mathrm{S}$ & $\mathrm{P}$ & $\mathrm{Cu}$ & $\mathrm{Ni}$ & $\mathrm{Cr}$ & $\mathrm{Mo}$ & $\mathrm{Al}$ & $\mathrm{V}$ & $\mathrm{Nb}$ & $\mathrm{Ti}$ & $\mathrm{N}$ \\
\hline 0.16 & 1.43 & 0.26 & $<0.01$ & 0.01 & 0.04 & 0.02 & 0.03 & $<0.01$ & 0.03 & 0.03 & 0.01 & $<0.01$ & $<0.01$ \\
\hline
\end{tabular}


Table 2 Process parameters used for each experiment

\begin{tabular}{lll}
\hline Differences & Experiment: & Laser defocus termination regime \\
\cline { 3 - 3 } & Abrupt laser termination & 3.30 \\
\hline Welding parameters: & & 0.25 \\
Laser power, $P,[\mathrm{~kW}]:$ & 4.65 & $0.6|3.0| 6.0$ \\
Laser travel speed, $v,[\mathrm{~m} / \mathrm{min}]:$ & 0.50 & As received \\
End laser spot diameter, $D_{\text {End }},[\mathrm{mm}]:$ & 0.6 & $300 \times 85 \times 7.7$ \\
Plate differences: & & $80|80| 80$ \\
Surface finish: & Machined & $7.0 \mid 0.1$ \\
Length $\times$ width $\times$ thickness, $[\mathrm{mm}]:$ & $200 \times 60 \times 8$ & $5277.9 \mid 75.4$ \\
Weld seam section length, $L_{\overrightarrow{A B}}\left|L_{\overrightarrow{B C}}\right| L_{\overrightarrow{C D}},[\mathrm{~mm}]:$ & $38|106| 44$ & $5209.3 \mid 6.8$ \\
Replicated circumferential welds: & & $0.60|0.25| 0.10$ \\
Pipe diameters, $D,[\mathrm{~m}]:$ & $226.2|94.3| 37.7$ & $195.6|63.7| 7.1$ \\
Circumference weld time, $t_{\text {circ }},[\mathrm{s}]:$ & &
\end{tabular}

${ }^{1} \mathrm{~A} t_{\overrightarrow{D A}} \approx 8 \mathrm{~s}$ and $11 \mathrm{~s}$ was used in the calculation for the $t_{\text {delay }}$ in the abrupt laser termination and laser defocus termination experiments, respectively

polished. These samples were all etched using $2 \%$ Nital solution. Vickers microhardness testing was carried out on the transverse cross-sectional weld samples across the weld area using a Zwick Roell hardness testing machine. A load of $500 \mathrm{~g}$ for $15 \mathrm{~s}$ was applied at $0.5-\mathrm{mm}$ spacing between indentations.

\subsection{Inter-pass temperature measurements}

The temperature measurements for the three weld samples in the abrupt laser termination experiment are shown in
Fig. 3. The thermal profile shows the effect of the different pipe diameter (or delay time) on the inter-pass temperature at the weld overlap region. The inter-pass temperature is the minimum recorded value before the temperature increases again when the second weld pass takes place. The residual heat from the first weld seam will affect the second weld seam from point $A$ to point $C$, and this was investigated accordingly.

For the laser defocusing termination regime experiment, the inter-pass temperature observed for the replicated pipe diameter of $0.1 \mathrm{~m}$ was $190{ }^{\circ} \mathrm{C}$.
Fig. 3 Temperature profile measurements of each weld sample from abrupt laser termination experiment

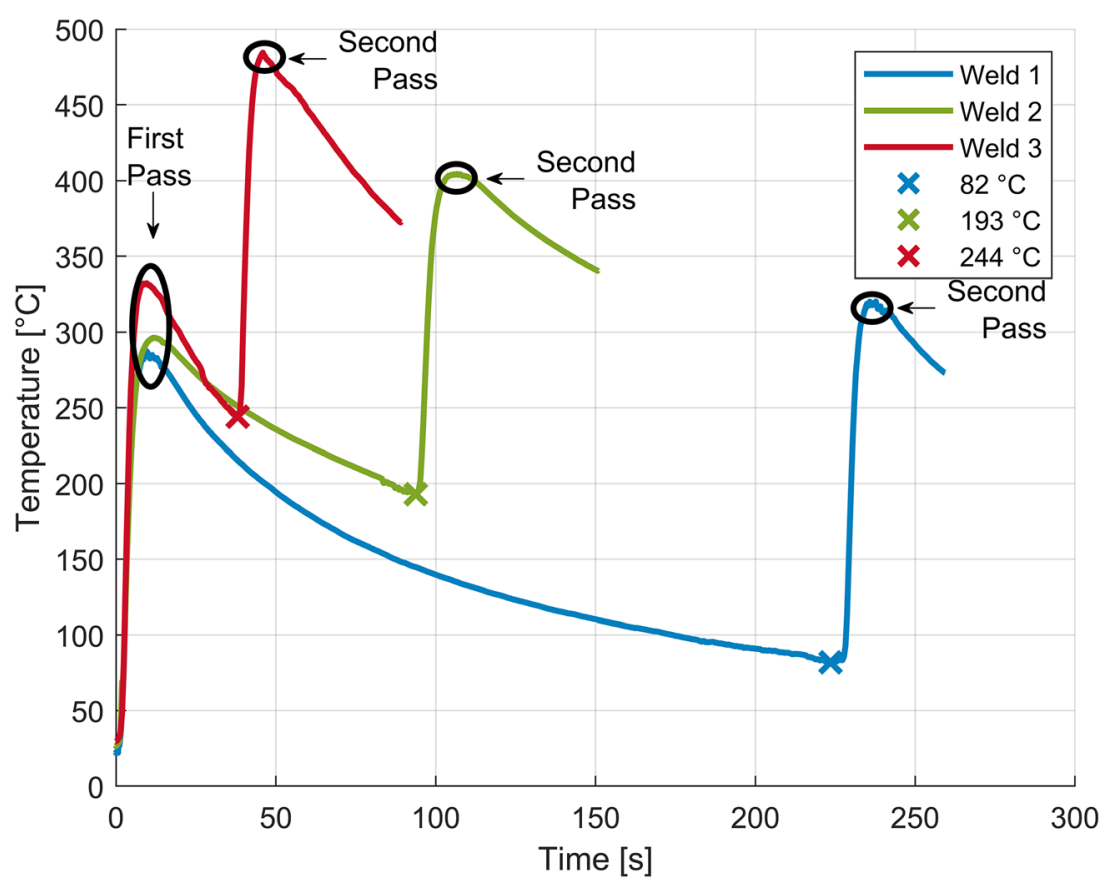




\section{Results and discussion}

\subsection{Effect of inter-pass temperature on the weld overlap start-stop region}

The inter-pass temperature at the weld overlap start-stop region is related to the circumferential diameter being welded and the process parameters used. For small diameter tubular sections or high travel speeds, the weld overlap would experience a high inter-pass temperature. This will affect the microstructure, weld properties, and the likelihood of defect formation.

\subsubsection{Weld profile}

Figure 4 shows the cross-sectional transverse macrographs, cut from the middle of the weld seam sections $\overrightarrow{A B}, \overrightarrow{B C}$, and $\overrightarrow{C D}$ for each weld sample from the abrupt laser termination experiment. The transverse macrograph of $\overrightarrow{C D}$ for all three weld samples was made with identical parameters on plates at room temperature.

When comparing the weld profile of section $\overrightarrow{C D}$ to $\overrightarrow{A B}$ and $\overrightarrow{B C}$, of each weld sample, respectively, the size of the heat- affected zone (HAZ) can be seen to increase with increasing inter-pass temperature. In weld sample 3, where the shortest delay time was applied, the second weld seam and weld overlap start-stop region experienced the highest inter-pass temperature. The size of the HAZ at the weld overlap start-stop region (transverse macrograph $\overrightarrow{B C}$ ) is, therefore, more significant. A small undercut is visible at the weld root which is likely to be a result of over-penetration and melt ejection, resulting in spatter.

On the other hand, the size of the fusion zone (FZ) of each respective weld sample remains similar despite the increase in inter-pass temperature and the weld being re-welded at the weld overlap start-stop region.

\subsubsection{Weld microstructure}

Figure 5 shows micrographs of the FZ taken from each weld seam section shown in Fig. 4. Micrographs of sections $\overrightarrow{C D}$ show a combination of pearlite with different morphologies of ferrite phases, such as grain boundary ferrite (GBF), polygonal ferrite (PF), and acicular/Widmanstätten ferrite (AF/WF).

Sections $\overrightarrow{A B}$ are similar in microstructure; however, in weld sample 2 and 3 , the influence of the higher inter-pass temperature can be observed. The microstructure at the FZ shows

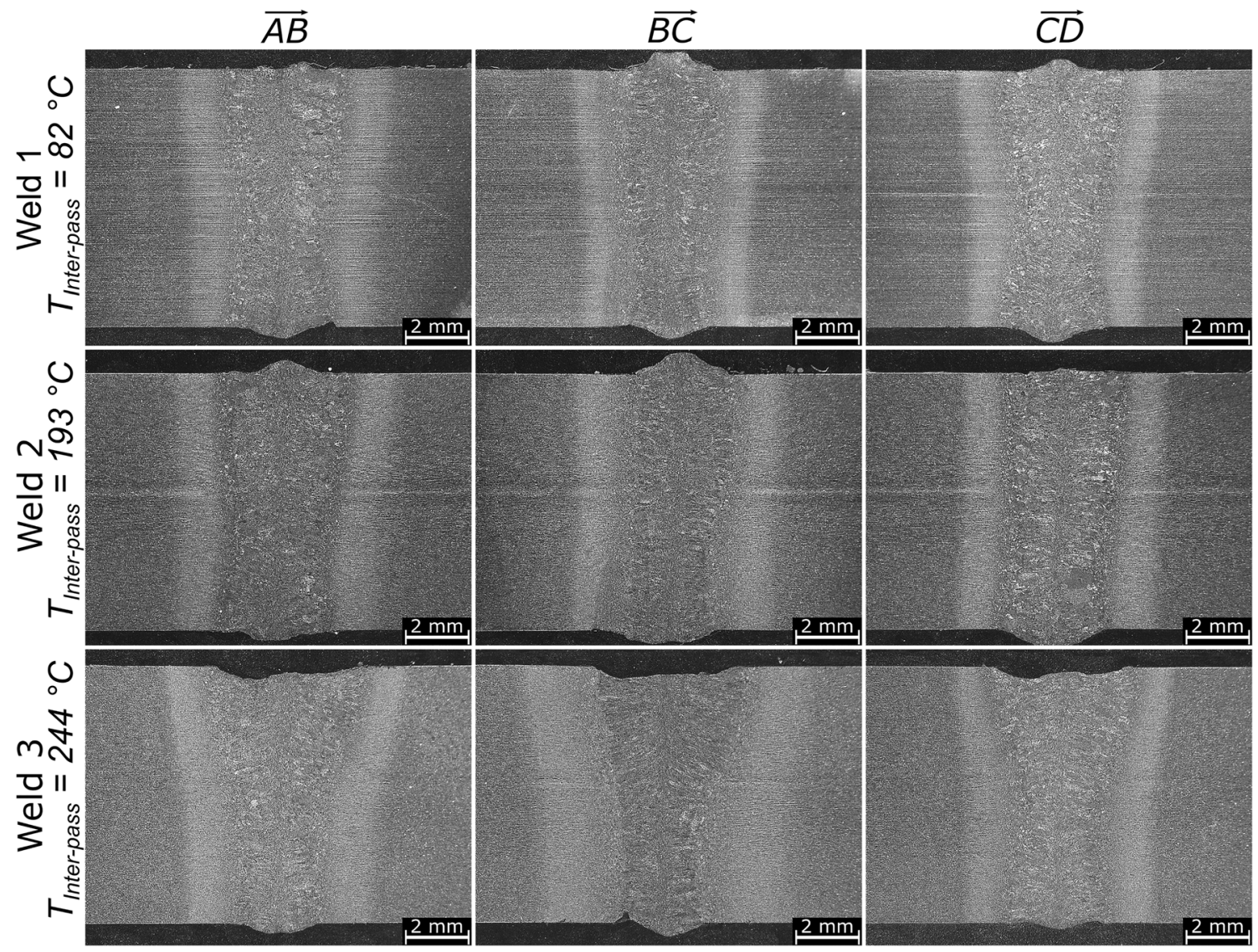

Fig. 4 Transverse macrographs from the middle of each weld seam section from the abrupt laser termination experiment 


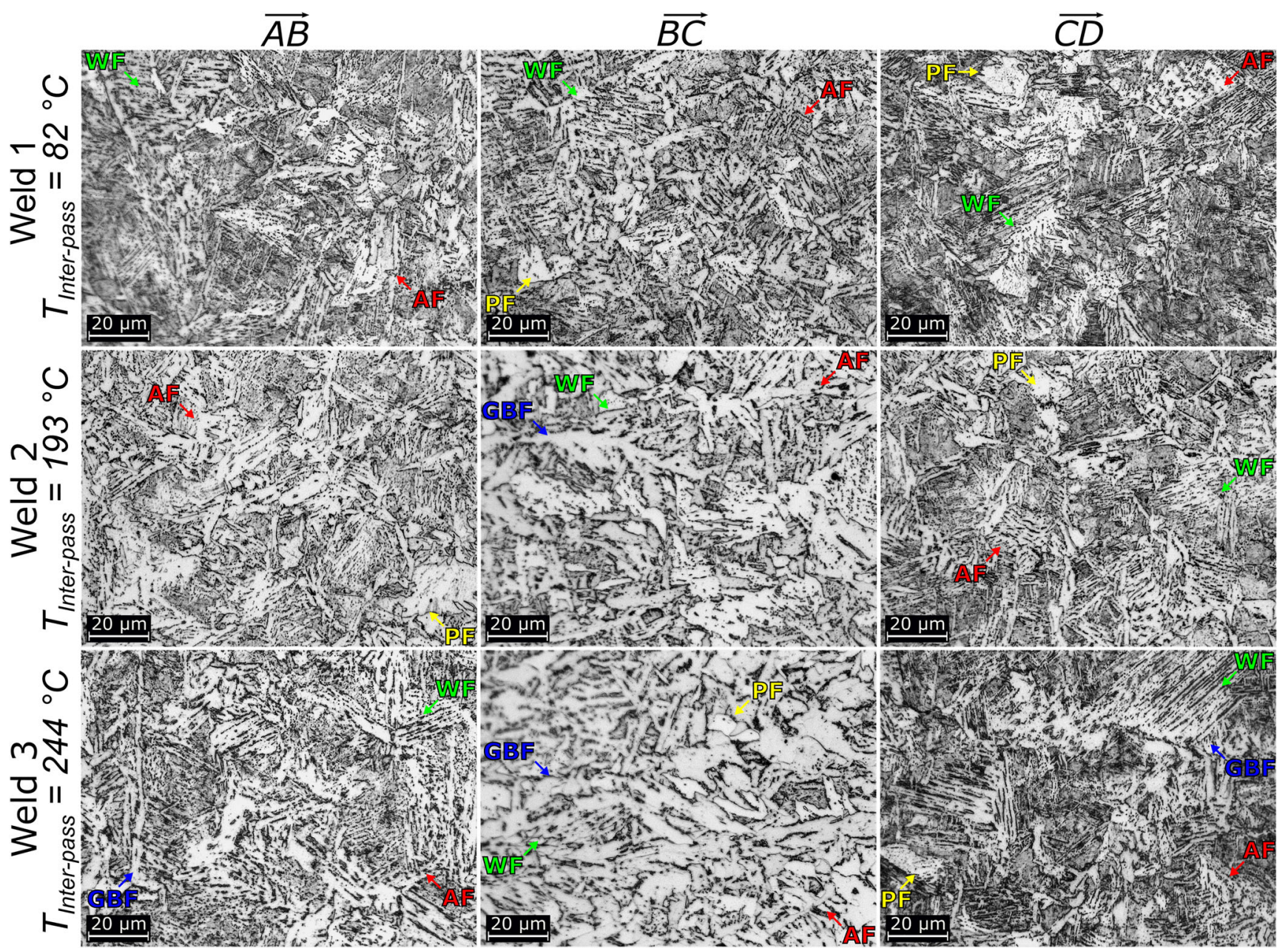

Fig. 5 Transverse micrographs of the FZ

more diffusion-controlled phases occurring. The amount of pearlite decreases while ferrite proportion increases with increasing inter-pass temperature. At the weld overlap start-stop region (section $\overrightarrow{B C}$ ), where the inter-pass temperature was at its maximum, there is a significant increase in size and volume fraction of ferrite phases, when compared with section $\overrightarrow{C D}$. In the weld overlap start-stop region of weld sample 3, the microstructure is predominantly ferrite. The increase in ferrite is due to the slower cooling rate experienced at the weld overlap achieved with the higher inter-pass temperature. However, there is a possible impact of ingress of reactive environmental gases on the microstructure in the absence of shielding gas but was not evaluated in this study.

\subsubsection{Weld microhardness}

Microhardness profiles across the weld centreline, along the mid-thickness of the transverse macrographs from Fig. 4, were measured.
Figure 6 shows the microhardness profiles of $\overrightarrow{A B}$ and $\overrightarrow{C D}$ from each weld sample. The microhardness profile and values shown are typical of welds made in S355 steels and are well below the maximum acceptable value of $350 \mathrm{HV}$ [21]. The minor variation in the microhardness profiles of weld seam sections of $\overrightarrow{C D}$ is expected despite identical parameters due to the variation in weld profile as previously mentioned. However, a small decrease in hardness across the weld can be observed when comparing $\overrightarrow{A B}$ with $\overrightarrow{C D}$ of each weld sample, respectively. The small decrease in hardness seen in sections $\overrightarrow{A B}$ of each weld sample is due to the influence of inter-pass temperature on the weld microstructure, as was observed in Fig. 5.

Figure 7 shows the microhardness profiles of $\overrightarrow{B C}$ from each weld sample compared with the average microhardness profile of $\overrightarrow{C D}$. The impact of the different inter-pass temperatures at the weld overlap start-stop region can be clearly seen. A significant decrease in hardness across the weld is observed when the weld overlap experienced the highest inter-pass temperature. There is little difference in hardness at the centreline of the three weld 
Fig. 6 Microhardness profiles at the mid-thickness across the weld centreline of weld seam sections $\overrightarrow{A B}$ and $\overrightarrow{C D}$ from each weld sample

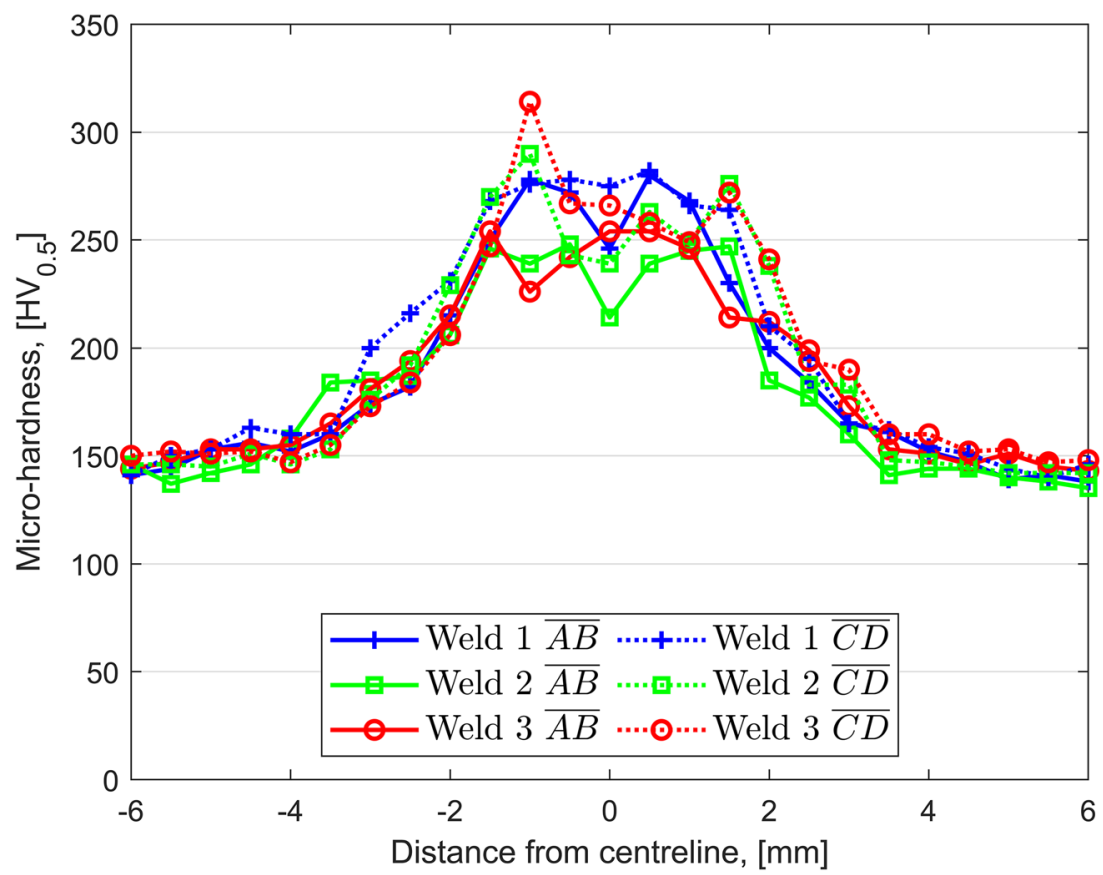

samples as there is no significant difference in cooling profile at the fusion zone as compared with the HAZ. The increase in HAZ at the weld overlap with increasing inter-pass temperature is also visible from the hardness profile, as shown in Fig. 7.

\subsubsection{Abrupt laser initiation and termination at the weld start-stop region}

Longitudinal macrographs of each laser initiation and termination points of each weld sample were taken and are shown in Fig. 8. Points $A$ and $D$ represent the initiation and termination of typical longitudinal weld, whereas points $B$ and $C$ represent the initiation and termination of a circumferential weld intersection.

At point $A$, where the laser is initiated, weld reinforcement can be seen on all samples; however, there are no observable internal defects, such as porosity present. At the termination point $D$, the defects observed are identical. Significant underfill in the form of deep weld craters or cavities are present on both the top and root surface at point $D$, as can be seen
Fig. 7 Microhardness profile at the mid-thickness across the weld centreline of weld seam sections $\overrightarrow{B C}$ of each weld sample

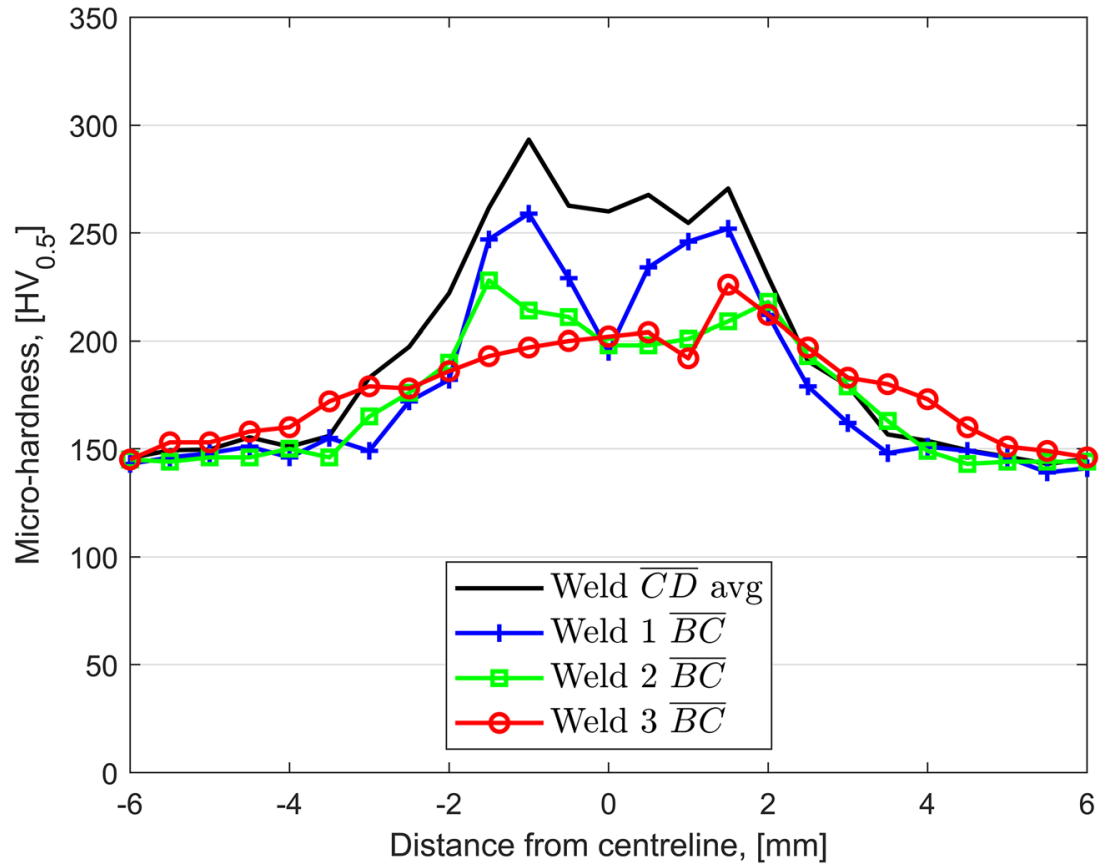



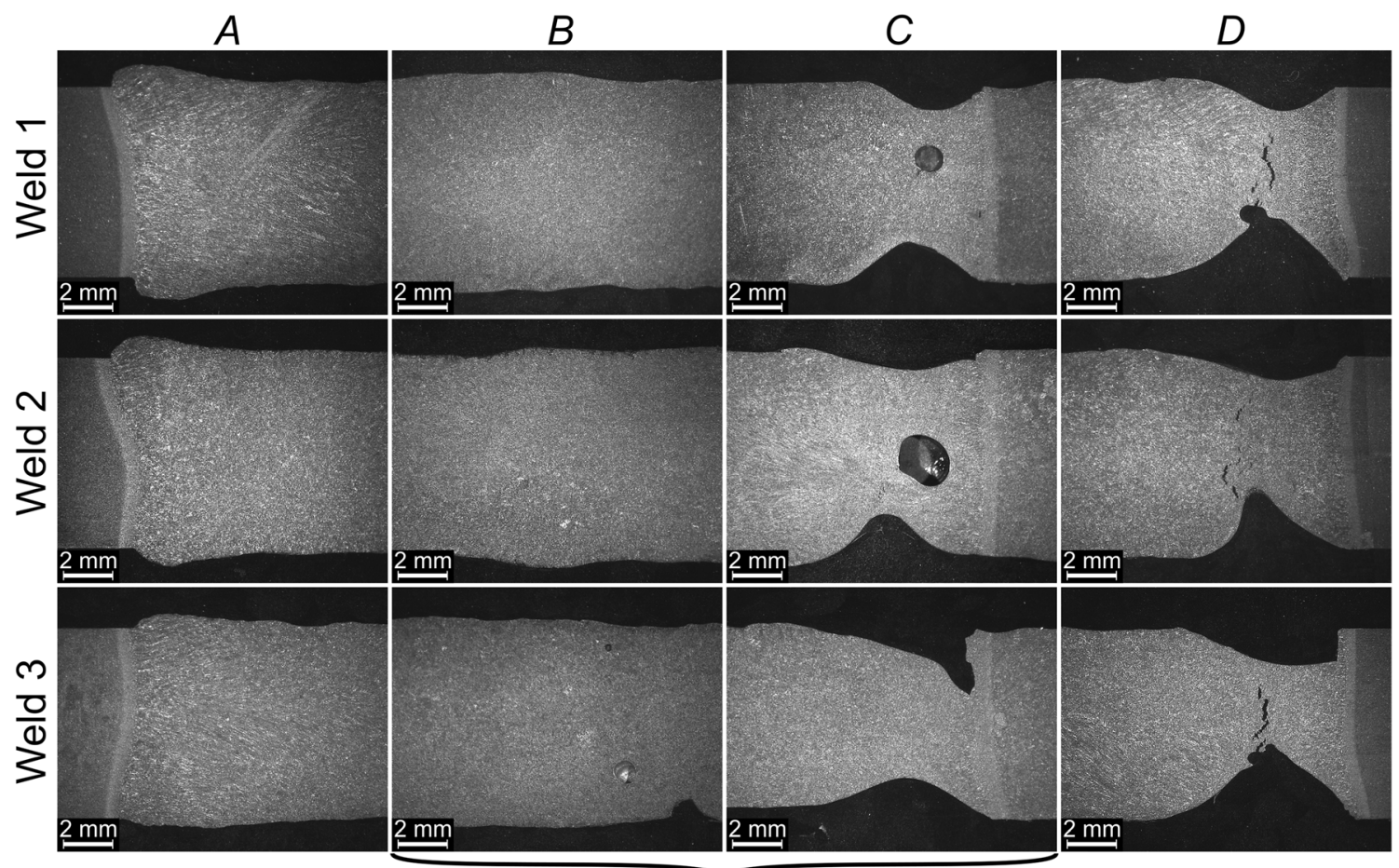

Weld start-stop region

Fig. 8 Longitudinal macrographs of the initiation and termination points of each weld sample

in Fig. 8. Solidification cracking perpendicular and through the thickness of the weld is also visible between the top and root weld craters. The cracks formed because of significant solidification stresses due to the large thermal gradient and difference in microstructure between the weld metal and parent metal.

At point $B$, the laser initiation point of the first weld seam is re-welded by the second weld seam. The weld reinforcement of the initiation point is re-melted and redistributed resulting in a more uniform transition in the weld surface. There are no observable defects in weld samples 1 and 2; however, in weld sample 3, a pore and weld root undercut are present. The location of the porosity and weld root undercut observed is about $4-5 \mathrm{~mm}$ after the laser initiation point of the first weld seam and not directly under the laser initiation point. Therefore, the pore is likely to have formed due to gas entrapment from the open keyhole root. The weld root undercut is likely due to over-penetration and melt ejection, resulting in spatter. The melt ejection at the weld root would also explain the gas entrapment located close to the undercut. The laser power should be decreased proportionally during the start of the weld overlap depending on the resultant inter-pass temperature to mitigate such defects.

At point $C$, weld craters or cavities are still present and still rather severe like at point $D$; however, there is no solidification cracking in either weld samples. The weld at point $C$ is less susceptible to cracking due to the similar microstructure and thermal gradient when compared with point $D$. In weld samples 1 and 2, a large pore and underfill at the weld top and root are present. The size of the pore is larger in weld sample 2 , which had a higher inter-pass temperature than weld sample 1. On the other hand, no pore present in weld sample 3 , which had the highest inter-pass temperature but the underfill at the weld top and root remains. The pore or void at point $C$ is a typical defect that occurs because of keyhole collapse, gas entrapment, and rapid solidification of the collapsed keyhole. At higher inter-pass temperatures, the solidification rate would reduce, allowing time for gases to escape and for the molten metal to stabilise and fill any voids caused by the keyhole collapse. However, despite the high inter-pass temperature allowing entrapped gases to escape and voids to be filled, the underfill present at both the weld top and root surface remains.

The inter-pass temperature has a negligible effect on the formation of laser keyhole termination-related defects, such as porosity and keyhole craters/cavities. The collapse of the keyhole is driven by keyhole dynamics during abrupt laser termination rather than the metallurgical aspects, such as the thermal cycle as defects were still present despite various weld thermal cycles. Different thermal cycles can lead to a reduced solidification rate, enabling entrapped gases from collapsed keyhole to escape but it does not prevent the formation of weld underfill defects at the top and root surface. However, the inter-pass temperature does affect the microstructural development and hardness profile, which needs to be considered to achieve the desired mechanical properties. 


\subsection{Effect of laser defocusing and inter-pass temper- ature on the weld start-stop region}

\subsubsection{Weld profile}

Visual inspections of the top surface of the weld start-stop region for each weld sample showed typical weld crater defects at point $\mathrm{C}$ in all weld samples regardless of laser termination regime and inter-pass temperature. The application of laser defocusing at the weld overlap also causes surface ripples to form on the top weld surface at a certain distance into the laser defocus as shown by Fig. 9. The formation of surface ripples is an indication of a change in melt flow behaviour. The ripples on the weld surface are unacceptable as the irregular surface roughness are stress concentration factors and is detrimental to the fatigue life of the welded structure. Therefore, to make the process more stable and avoid these phenomena, a simultaneous decrease in laser power is recommended.

Figure 10 shows the longitudinal macrographs in-between points $B$ and $C$ where full penetration ceases, and the location where the macrographs were taken. The HAZ of the second weld seam has again been highlighted to show the different weld profiles.

The transition from full penetration to partial penetration and resulting change in penetration depth when laser defocusing is steeper with the larger end laser spot diameter. The penetration depth begins to stabilise after a certain point of laser defocusing and coincides with the surface ripple formation. There are no observable internal defects, such as porosity within this region, indicating that keyhole collapse was avoided and that a stable, successful keyhole closure was achieved regardless of the inter-pass temperature.

\subsubsection{Weld microhardness}

A visual representation of the microhardness profiles projected on top of the corresponding traverse crosssectional macrographs of each weld sample is shown in Fig. 11. These weld samples were taken $30 \mathrm{~mm}$ from the termination point. Where no defocusing was applied at the weld overlap, a slight decrease in weld microhardness across the weld is observed at the higher inter-pass temperature.

The two different weld seam areas show the effect of the laser defocusing weld overlap on the weld profile. The HAZ of the overlapping weld seam can be clearly distinguished from the previous weld seam and increases in size at higher inter-pass temperatures. The microhardness profiles through the thickness, therefore, vary as a result. At the top of the weld, an increase in hardness can be observed at the liquid-solid boundary of the second weld seam overlap. However, at a higher inter-pass temperature, the microhardness profile at the top of the weld does not see an increase and is more uniform. An overall reduction of $6 \%, 4.6 \%$, and $0.87 \%$ for a $D_{\text {End }}$ of $0.6 \mathrm{~mm}, 3 \mathrm{~mm}$, and $6 \mathrm{~mm}$, respectively, is seen when comparing an inter-pass temperature of $20^{\circ} \mathrm{C}$ to an inter-pass temperature of $190^{\circ} \mathrm{C}$.

Control of the inter-pass temperature and laser defocusing termination regime is essential as the microhardness profile is dependent on these factors. Too large a diameter or slow travel speed leads to excessive cooling between completions of the weld seam. As a result, this may induce hard microstructural phases in the weld overlap start-stop region.

\subsubsection{Weld start-stop laser termination}

The top surface and longitudinal macrographs of the termination point and weld craters for each set of laser end spot diameters and inter-pass temperatures are shown in Fig. 12. The HAZ of the second weld seam has been highlighted to show the difference in weld profile and penetration depth. When the laser terminates after laser defocusing, a shallow depression at the termination point in the form of a weld crater remains and could be further optimised. There are marginal differences in the appearance of the weld crater when terminating using laser defocusing at a higher inter-pass temperature. The higher thermal energy within the material leads to increased melting, and this is observed by the increased size of the melt pool and HAZ resulting in a slightly larger weld crater upon laser termination.

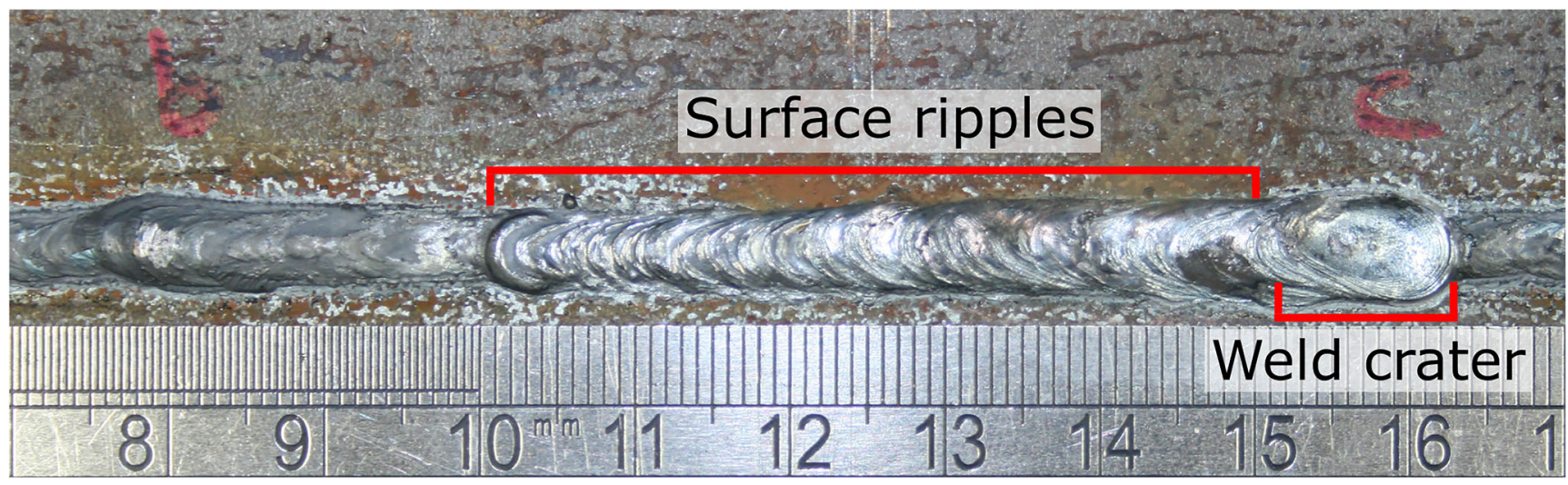

Fig. 9 Top surface of the weld overlap start-stop region where the laser defocusing termination regime was applied 


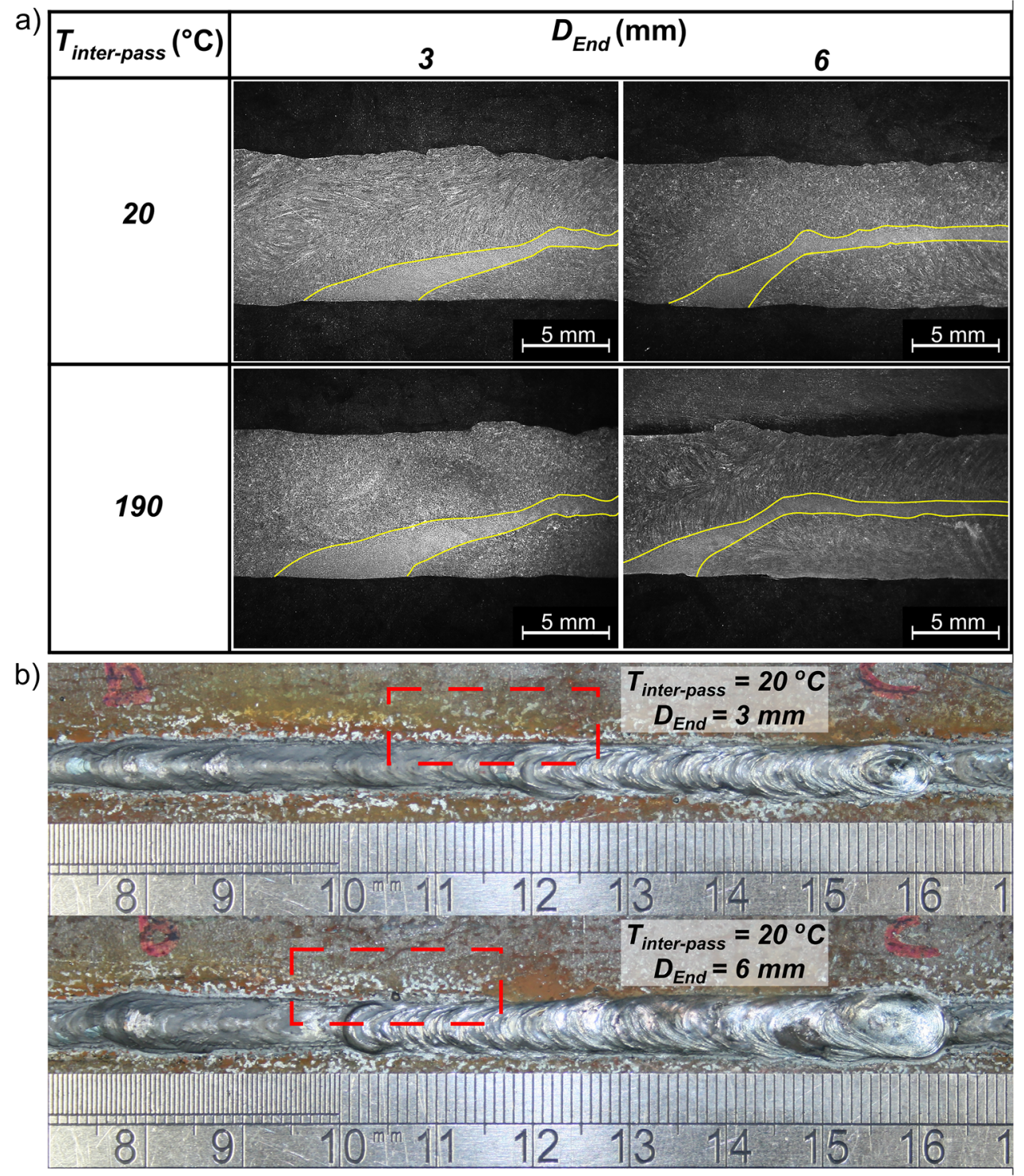

Fig. 10 (a) Longitudinal macrographs of weld transition to partial penetration due to laser defocusing, (b) location where macrographs were taken indicated by dashed-line rectangles

No internal defects, such as porosity or cracking, are present at the termination point where laser defocusing was applied.

\section{Conclusion}

In this study, the effect of abrupt laser termination and the application of laser defocusing termination regime at the weld overlap start-stop region of 8-mm-thick S355 structural steel plates were investigated under different inter-pass temperatures.

- It was identified that abrupt laser termination leads to the formation of defects, such as underfills in the form of deep weld craters or cavities, pores, and solidification cracking when compared with abrupt laser initiation.
- In circumferential welds, defects occurring within the weld overlap start-stop region were due to laser termination rather than laser initiation because of keyhole instabilities and collapse. The laser termination-related defects are present regardless of the inter-pass temperature indicating that keyhole closure and collapse are dependent on and driven by keyhole dynamics rather than the metallurgical aspects, such as the thermal cycle. However, the inter-pass temperature does affect the microstructural development and hardness profile.

- The similar microstructure and residual heat between the start section of the weld and the new termination point prevent cracking from occurring. However, this is still dependent on the thickness and circumference of the workpiece being welded. Other defects, such as deep weld 


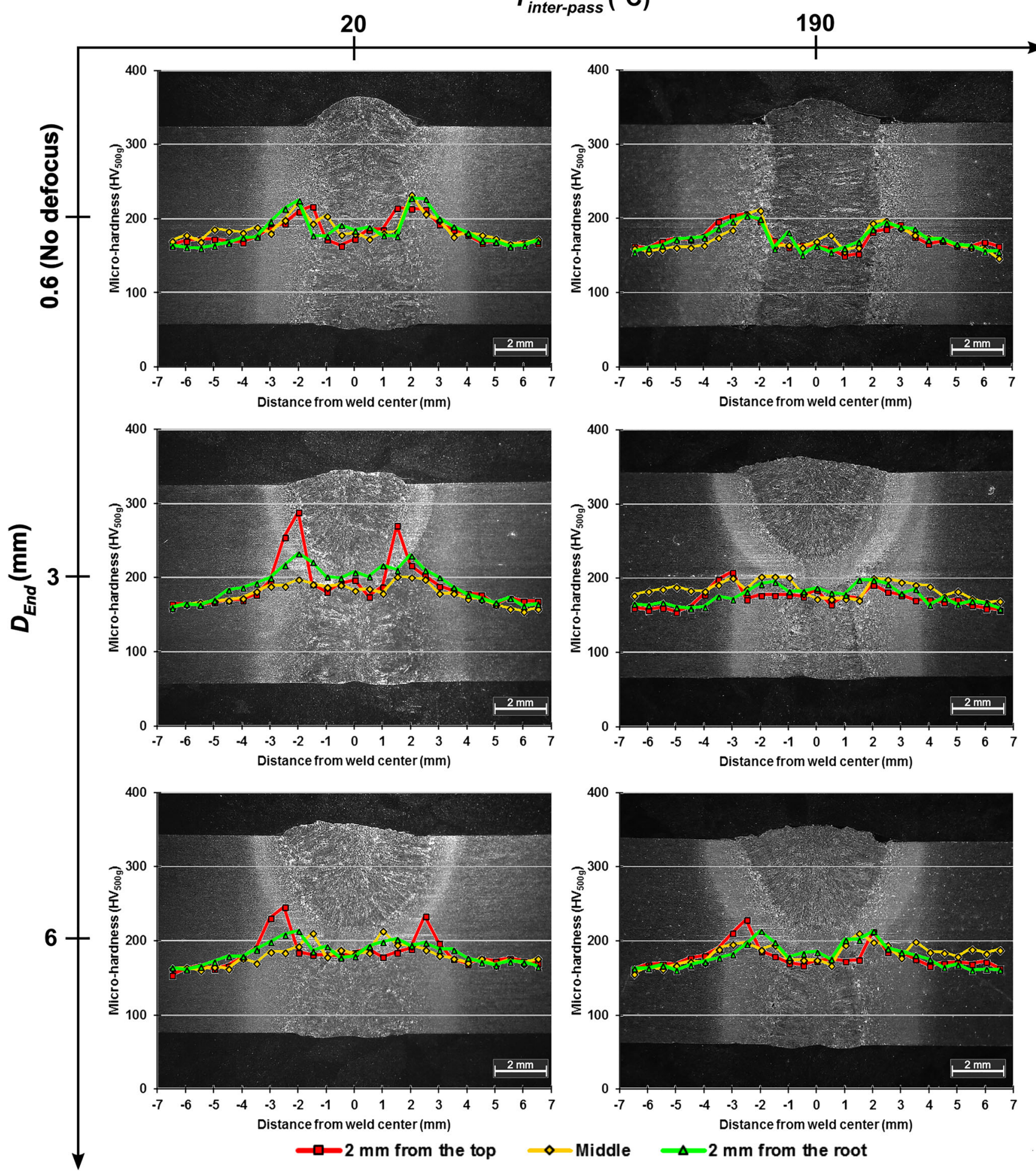

Fig. 11 Microhardness profiles projected onto transverse macrographs of the weld overlap for each weld sample

craters and porosity, remain when the laser is terminated abruptly.

- Laser keyhole closure was successfully achieved by applying a laser defocusing termination regime. Controlled termination of the laser was implemented by linear defocusing of the laser spot diameter by moving the laser head. This ensured a gradual reduction of the applied power density and keyhole depth prior to laser termination. Laser termination-related defects, such as deep weld craters and porosity, are eliminated as keyhole collapse is 


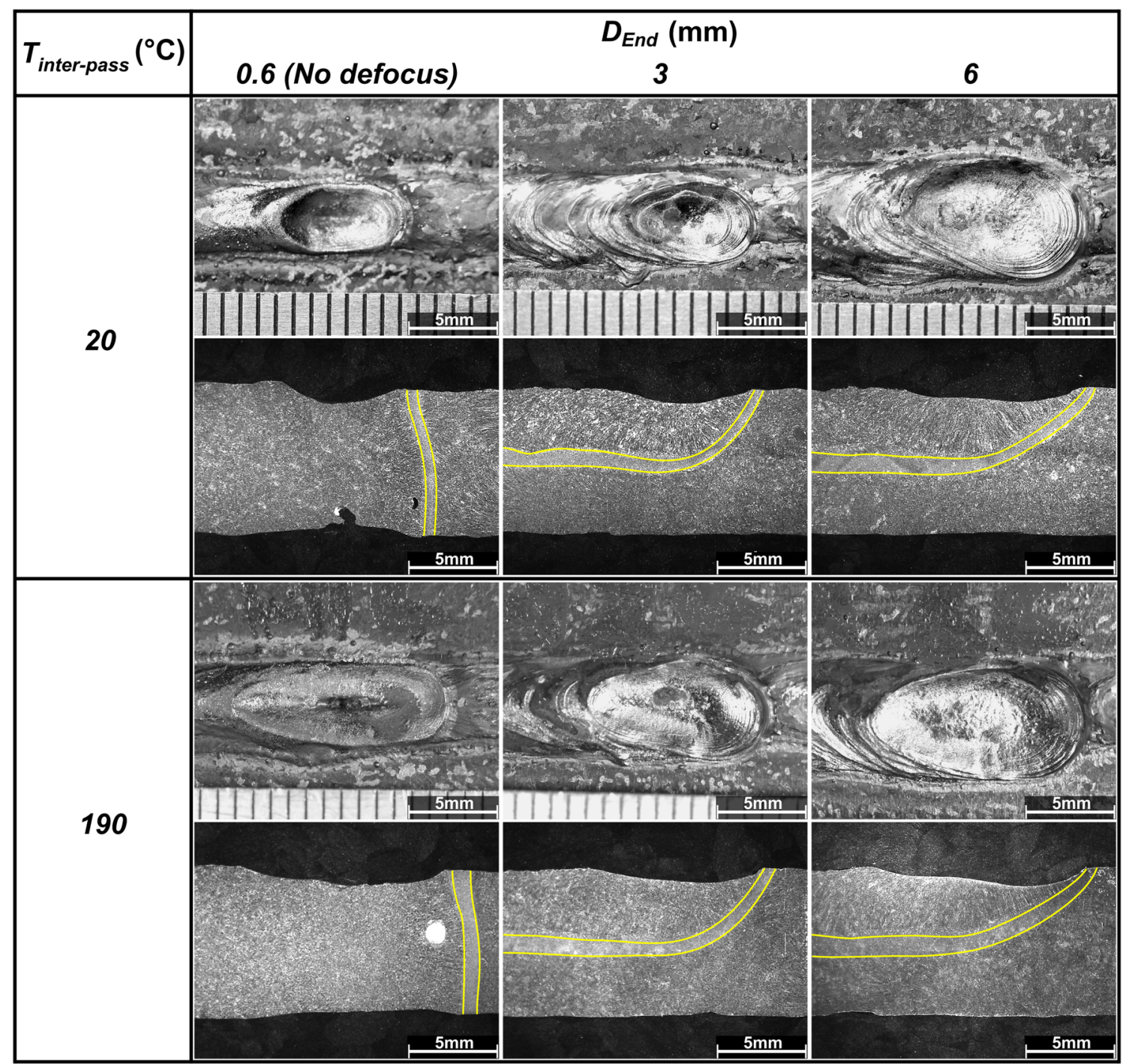

Fig. 12 Top surface and longitudinal macrograph of termination point $C$ at different laser defocus end spot diameters and inter-pass temperatures

avoided during termination. However, surface ripples and a depression in the form of a shallow weld crater remain on the top surface. Further optimisation of the process parameters is required to achieve a defect-free laser circumferential weld.

Author contribution Wai Jun Lai: Conceptualisation, formal analysis, investigation, writing - original draft, visualisation.

Supriyo Ganguly: Conceptualisation, supervision, writing-review and editing.

Wojciech Suder: Conceptualisation, supervision, writing — review and editing.

Funding This work was financially supported by grant EP/L016303/1 for Cranfield University, Centre for Doctoral Training in Renewable Energy Marine Structures (REMS) (http://www.rems-cdt.ac.uk/) from the UK Engineering and Physical Sciences Research Council (EPSRC).

Data availability All data are presented within the manuscript.
Code availability Not applicable.

\section{Declarations}

Ethical approval The article follows the guidelines of the Committee on Publication Ethics (COPE) and involves no studies on human or animal subjects.

Consent to participate Not applicable. The article involves no studies on humans.

Consent to publish Not applicable. The article involves no studies on humans

Competing interests The authors declare no competing interests.

Open Access This article is licensed under a Creative Commons Attribution 4.0 International License, which permits use, sharing, adaptation, distribution and reproduction in any medium or format, as long as you give appropriate credit to the original author(s) and the source, provide a link to the Creative Commons licence, and indicate if changes were 
made. The images or other third party material in this article are included in the article's Creative Commons licence, unless indicated otherwise in a credit line to the material. If material is not included in the article's Creative Commons licence and your intended use is not permitted by statutory regulation or exceeds the permitted use, you will need to obtain permission directly from the copyright holder. To view a copy of this licence, visit http://creativecommons.org/licenses/by/4.0/.

\section{References}

1. Mingareev I, Weirauch F, Olowinsky A, Shah L, Kadwani P, Richardson M (2012) Welding of polymers using a $2 \mu \mathrm{m}$ thulium fiber laser. Opt Laser Technol 44:2095-2099. https://doi.org/10. 1016/j.optlastec.2012.03.020

2. Schubert E, Klassen M, Zerner I, Walz C, Sepold G (2001) Lightweight structures produced by laser beam joining for future applications in automobile and aerospace industry. $\mathrm{J}$ Mater Process Technol 115:2-8. https://doi.org/10.1016/S0924-0136(01)00756-7

3. Naeem M (2013) Laser processing of reflective materials. Laser Tech J 10:18-20. https://doi.org/10.1002/latj.201390001

4. Mai TA, Spowage AC (2004) Characterisation of dissimilar joints in laser welding of steel-kovar, copper-steel and copper-aluminium. Mater Sci Eng A 374:224-233. https://doi.org/10.1016/j.msea. 2004.02.025

5. Roland F, Reinert T, Pethan G (2003) Laser welding in shipbuilding - an overview of the activities at Meyer Werft. Weld Res Abroad 49:39-51

6. Moore PL, Howse DS, Wallach ER (2004) Microstructures and properties of laser/arc hybrid welds and autogenous laser welds in pipeline steels. Sci Technol Weld Join 9:314-322. https://doi.org/ $10.1179 / 136217104225021652$

7. Gook S, Gumenyuk A, Rethmeier M (2014) Hybrid laser arc welding of X80 and X120 steel grade. Sci Technol Weld Join 19: 15-24. https://doi.org/10.1179/1362171813Y.0000000154

8. Kristiansen M, Farrokhi F, Kristiansen E, Villumsen S (2017) Application of hybrid laser arc welding for the joining of large offshore steel foundations. Phys Procedia 89:197-204. https://doi. org/10.1016/j.phpro.2017.08.018

9. Walsh C. Laser welding - literature review. England: 2002.
10. Pastor M, Zhao H, Debroy T (2001) Pore formation during continuous wave Nd:YAG laser welding of aluminium for automotive applications. Weld Int 15:275-281. https://doi.org/10.1080/ 09507110109549355

11. Lee JY, Ko SH, Farson DF, Yoo CD (2002) Mechanism of keyhole formation and stability in stationary laser welding. J Phys D Appl Phys 35:1570-1576. https://doi.org/10.1088/0022-3727/35/13/320

12. Zhao H, Niu W, Zhang B, Lei Y, Kodama M, Ishide T (2011) Modelling of keyhole dynamics and porosity formation considering the adaptive keyhole shape and three-phase coupling during deeppenetration laser welding. J Phys D Appl Phys 44:485302

13. Dawes C (1992) Laser welding: a practical guide. Abington Publishing, Cambridge

14. Kroos J, Gratzke U, Vicanek M, Simon G (1993) Dynamic behavior of the keyhole in laser welding. J Phy D 26:481-486. https://doi. org/10.1088/0022-3727/26/3/022

15. Courtois M, Carin M, Le Masson P, Gaied S, Balabane M (2014) A complete model of keyhole and melt pool dynamics to analyze instabilities and collapse during laser welding. J Laser Appl 26: 042001. https://doi.org/10.2351/1.4886835

16. Becker W, Beck M, Goth K, Paelmer M, Reiniger C-D, Zauner D. Process for laser beam welding with reduced formation of end craters. US 7,091,444 B2, 2006.

17. Gook S, Üstündağ Ö, Gumenyuk A, Rethmeier M (2020) Avoidance of end crater imperfections at high-power laser beam welding of closed circumferential welds. Weld World 64:407-417. https://doi.org/10.1007/s40194-019-00841-x

18. Powell J, Ilar T, Frostevarg J, Torkamany MJ, Na S-J, Petring D, Zhang L, Kaplan AFH (2015) Weld root instabilities in fiber laser welding. J Laser Appl 27:S29008. https://doi.org/10.2351/1. 4906390

19. $\mathrm{Xu} \mathrm{Z}$. Laser welding and post weld treatment of modified $9 \mathrm{Cr}-$ $1 \mathrm{MoVNb}$ steel. 2008.

20. Suder WJ, Williams S (2014) Power factor model for selection of welding parameters in CW laser welding. Opt Laser Technol 56: 223-229. https://doi.org/10.1016/j.optlastec.2013.08.016

21. DNV GL. DNVGL-OS-C401: fabrication and testing of offshore structures. July 2020. n.d.

Publisher's note Springer Nature remains neutral with regard to jurisdictional claims in published maps and institutional affiliations. 